\title{
Loss of skeletal muscle mass after curative gastrectomy is a poor prognostic factor
}

\author{
NARUJI KUGIMIYA ${ }^{1}$, EIJIRO HARADA ${ }^{1}$, KAZUHITO OKA ${ }^{2}$, DAICHI KAWAMURA ${ }^{1}$, \\ YUKI SUEHIRO $^{1}$, YOSHIHIRO TAKEMOTO ${ }^{1}$ and KIMIKAZU HAMANO ${ }^{1}$
}

${ }^{1}$ Department of Surgery and Clinical Science, Yamaguchi University Graduate School of Medicine, Ube, Yamaguchi 755-8505;
${ }^{2}$ Department of Surgery, Saiseikai Shimonoseki General Hospital, Shimonoseki, Yamaguchi 759-6603, Japan

Received June 27, 2017; Accepted April 30, 2018

DOI: $10.3892 / \mathrm{ol} .2018 .8747$

\begin{abstract}
Sarcopenia has been reported to relate to poor prognosis in various malignant cancer types. The present study aimed to clarify the prognostic impact of skeletal muscle mass (SMM) loss after curative gastrectomy in patients with gastric cancer. A total of 119 patients who underwent curative gastrectomy for gastric cancer between 2009 and 2016 were analyzed. The SMM loss at 6 months postoperatively compared with the SMM prior to surgery was calculated using the hospital records. The median loss of SMM was $3.8 \%$. Multivariate logistic regression analysis demonstrated that total gastrectomy was a significant and independent risk factor for SMM loss of $\geq 5 \%$ (odds ratio=2.58; $\mathrm{P}=0.02$ ). Results from multivariate analysis using stepwise Cox proportional hazards regression indicated that the following factors were significantly associated with shorter overall survival after curative gastrectomy: Age [ $>70$ years; hazard ratio $(\mathrm{HR})=2.46$, $\mathrm{P}=0.04]$, TNM stage $(\geq 2 ; \mathrm{HR}=2.65, \mathrm{P}=0.04)$ and loss of $\mathrm{SMM}$ $(\geq 5 \%$; $\mathrm{HR}=2.57, \mathrm{P}=0.03)$. The present findings suggested that loss of SMM after curative gastrectomy for gastric cancer is an independent predictive factor for poor prognosis.
\end{abstract}

\section{Introduction}

In 1989, Rosenberg first advocated the term 'sarcopenia' for reductions in muscle mass due to aging (1). Sarcopenia is a syndrome characterized by progressive and generalized loss of skeletal muscle mass (SMM) and strength, and is associated with increased risks of adverse outcomes such as physical disability, frailty, poor quality of life, and mortality. Sarcopenia has been reported to relate to poor prognosis in many malignant cancers, including hepatocellular carcinoma (2), lung cancer (3), bladder cancer (4), pancreatic

Correspondence to: Dr Eijiro Harada, Department of Surgery and Clinical Science, Yamaguchi University Graduate School of Medicine, 1-1-1 Minami-Kogushi, Ube, Yamaguchi 755-8505, Japan E-mail: eharada@yamaguchi-u.ac.jp

Key words: skeletal muscle mass, gastric cancer, gastrectomy, prognosis cancer (5), melanoma (6), and colorectal cancer $(7,8)$. By clarifying the mechanisms of sarcopenia, it may be possible to improve the prognosis of patients with sarcopenia. In addition, understanding the mechanisms of sarcopenia may also help elucidate the mechanisms of cachexia.

In gastric cancer, preoperative sarcopenia has been shown to be a predictive marker of postoperative complications and poor prognosis (9). In two previous studies, a $6.2 \%$ loss of skeletal muscle was observed after total gastrectomy (10), and adjuvant chemotherapy with S-1 was identified as an independent risk factor for significant loss of skeletal muscle (11). Moreover, reductions of lean body muscle mass after gastrectomy has been reported to prevent the continuation of adjuvant chemotherapy (12). Despite this prior evidence, however, the effect of postoperative SMM loss on long-term survival remains unclear.

With this in mind, the aim of the present study was to clarify: i) the factors that cause loss of SMM at 6 months post-gastrectomy; and ii) the impact of postoperative SMM loss on prognosis.

\section{Patients and methods}

Patients. The present study enrolled patients with gastric cancer who underwent curative surgery with nodal dissection at Yamaguchi University Hospital (Yamaguchi, Japan) between January 2009 and April 2016. Computed tomography (CT) was performed within 1 month before surgery and at 6 months postoperatively. Patients who relapsed within 6 months or did not undergo CT examination at these fixed times were excluded.

Data collection. All relevant data, including the clinical, surgical, and pathological records, were collected retrospectively from the database of our hospital. All cancers were staged in accordance with the tumor node metastasis (TNM) classification system used in the 14th edition of the Japanese Gastric Cancer Classification.

Measurement of SMM. A skeletal muscle area was measured retrospectively on CT scans performed before gastrectomy and 6 months after surgery. The muscle area was evaluated at the level of the third lumbar vertebra (L3) in the inferior direction, with the patient in the supine position. Cross-sectional areas 
$\left(\mathrm{cm}^{2}\right)$ of skeletal muscles in the L3 region were measured using AZE Virtual Place image analysis software (AZE, Tokyo, Japan). SMM was identified by Hounsfield unit thresholds of -30 to +150 on CT. A SMM index was defined such that the cross-sectional areas were normalized for the patient height $\left(\mathrm{cm}^{2} / \mathrm{m}^{2}\right)$.

Statistical analysis. Statistical analyses were performed using SPSS version 22 for Windows (IBM Corp., Armonk, NY, USA). The percentage loss of skeletal body muscle mass was defined as follows: Percentage loss of SMM=(skeletal body muscle mass 6 months after surgery/preoperative skeletal body muscle mass) x100. Subsequently, the patients were divided into two groups based on the percentage loss of SMM: $<5$ vs. $\geq 5 \%$. Each of the remaining cutoff values, including the operation time, surgical blood loss, and SMM, was set at the median point of the recorded values. Surgical complications were classified according to the Clavien-Dindo classification.

Differences between groups were analyzed using the t-test or $\chi^{2}$ test, as appropriate. Univariate and multivariate logistic regression analyses were performed to identify risk factors for loss of SMM. Cox proportional hazards regression models were used to identify variables associated with relapse-free survival (RFS) or overall survival (OS). Backward stepwise elimination with a threshold of $\mathrm{P}=0.10$ was used to select the variables to be included. Survival curves were generated using the Kaplan-Meier method and compared using the log-rank test. For all analyses, $\mathrm{P}<0.05$ was considered to indicate a statistically significant difference.

\section{Results}

Patients. From January 2009 to April 2016, a total of 119 patients met our inclusion criteria and were included in the analysis. The median follow-up time for these patients was 30.9 months (range; 7.3-94.0 months).

The median loss of SMM was 3.8\%. Histograms showing the loss of SMM in this study are presented in Fig. 1. A SMM loss of $\geq 5 \%$ was noted in 51 patients $(42.9 \%)$. Patients with a SMM loss of $\geq 5 \%$ showed a significantly higher preoperative SMM index than those with a SMM loss $<5 \%(\mathrm{P}=0.005)$, and showed a significantly higher frequency of total gastrectomy ( $\mathrm{P}=0.01$; Table I).

Risk factors for loss of SMM. The risk factors for SMM loss $\geq 5 \%$ were investigated using univariate and multivariate analyses including clinical, surgical, and pathological factors. The results are shown in Table II. In the multivariate analysis, total gastrectomy was the only independent predictor of the loss of SMM $(\mathrm{P}=0.02)$.

Loss of SMM and RFS. In the univariate Cox proportional hazards regression analyses, the following variables were significantly associated with worse RFS: Lymphadenectomy (D1+; $\mathrm{P}=0.04)$, operation time ( $>309 \mathrm{~min} ; \mathrm{P}=0.01)$, T stage $(\geq 2$; $\mathrm{P}=0.005)$, $\mathrm{N}$ stage ( $\geq 1 ; \mathrm{P}=0.001)$, TNM stage $(\geq 2 ; \mathrm{P}=0.002)$, adjuvant chemotherapy (present; $\mathrm{P}=0.001$ ), and loss of SMM $(\geq 5 \%$; $\mathrm{P}=0.01$; Table III). Furthermore, in the multivariate analysis using a stepwise Cox model, adjuvant chemotherapy (present; $\mathrm{P}=0.001$ ) remained significantly associated with worse RFS (Table III).

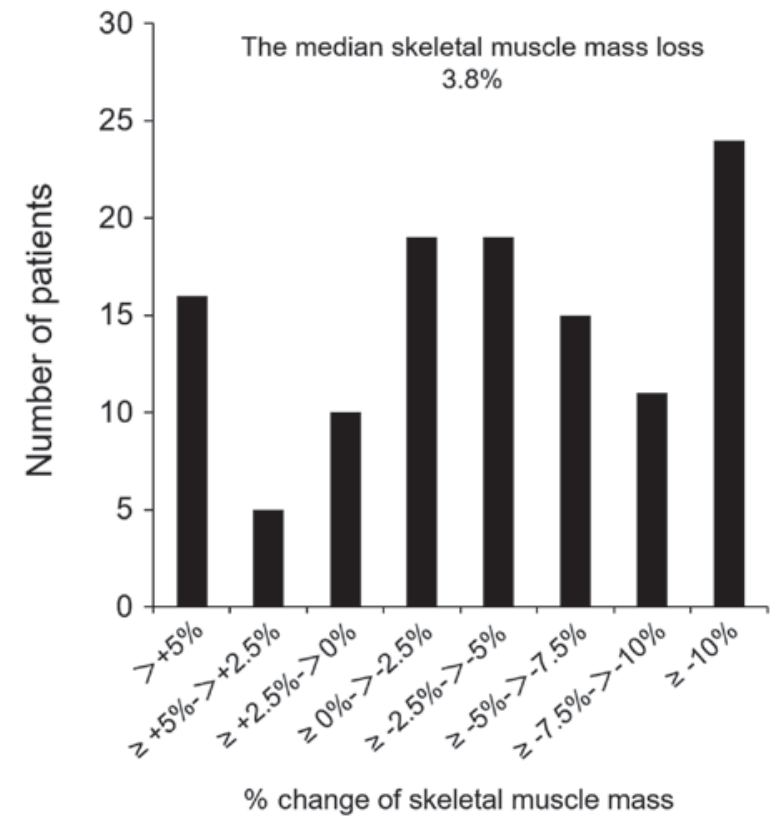

Figure 1. Histogram of the \% skeletal muscle mass loss. Percentage change of skeletal muscle mass was measured (6 month after surgery skeletal muscle mass/preoperative skeletal muscle mass) x100.

Loss of SMM and OS. In the univariate Cox regression analyses, the following variables were significantly associated with worse OS: T stage ( $\geq 2 ; \mathrm{P}=0.03)$, TNM stage $(\geq 2 ; \mathrm{P}=0.03)$, and loss of SMM ( $\geq 5 \% ; \mathrm{P}=0.04$; Table IV). In the multivariate analysis using a stepwise Cox model, age ( $>70$ years; $\mathrm{P}=0.04)$, TNM stage $(\geq 2 ; \mathrm{P}=0.04)$, and loss of SMM $(\geq 5 \% ; \mathrm{P}=0.03)$ were found to be significantly associated with poor prognosis after curative gastrectomy (Table IV).

In the Kaplan-Meier analysis, patients with a SMM loss of $\geq 5 \%$ experienced significantly shorter 5 -year RFS ( 62.2 vs. $79.9 \%$, $\log$-rank $\mathrm{P}=0.008)$ and OS (64.5 vs. $84.2 \%, \log$-rank $\mathrm{P}=0.039)$ than those with a SMM loss $<5 \%$ (Fig. 2A and E). Among patients with TNM stage II disease, the 5-year OS was remarkably shorter for patients with SMM loss of $\geq 5 \%$ than for those SMM loss of $<5 \%$ (55.8 vs. $90.9 \%, \log$-rank $\mathrm{P}=0.03$; Fig. $2 \mathrm{G}$ ).

\section{Discussion}

This study was designed to evaluate the relation between postoperative SMM loss and 5-year survival in gastric cancer patients after gastrectomy. First, we investigated the risk factors for loss of SMM at 6 months after gastrectomy. In this study, the median loss of SMM was 3.8\% at 6 months after gastrectomy. Other authors have reported that the body weight loss at 1 month postoperatively was 6\% (13) and that the loss of lean body mass was $4.7 \%$ (10). In these studies, the risk factors for reductions in the body mass index were found to include male sex, higher preoperative body mass index, total gastrectomy, and advanced TNM stage (13), while the independent risk factors for severe lean body mass loss were surgical complications, total gastrectomy, and male sex (10). In the present study, total gastrectomy was the only independent risk factor for SMM loss at 6 months after gastrectomy.

After total gastrectomy, the body weight, lean body mass, and SMM all decreased. Reduced oral intake is commonly 
Table I. Comparison of the clinicopathological and surgical factors between patients with a loss of SMM $<5 \%$ vs. $\geq 5 \%$ at 6 months after gastrectomy.

\begin{tabular}{|c|c|c|c|}
\hline Factors & $\begin{array}{l}\text { Loss of skeletal muscle } \\
\text { mass }<5 \%(\mathrm{~N}=68) \mathrm{N}(\%)\end{array}$ & $\begin{array}{l}\text { Loss of skeletal muscle } \\
\text { mass } \geq 5 \%(\mathrm{~N}=51) \mathrm{N}(\%)\end{array}$ & P-value \\
\hline Age & $70.8 \pm 10.4$ & $69.7 \pm 10.3$ & 0.56 \\
\hline Sex & & & 0.14 \\
\hline Male & $42(61.8)$ & $38(74.5)$ & \\
\hline Female & $26(38.2)$ & $13(25.5)$ & \\
\hline BMI: $\mathrm{kg} / \mathrm{m}^{2}$ & $22.9 \pm 3.2$ & $23.0 \pm 3.7$ & 0.86 \\
\hline SMM Index: $\mathrm{cm}^{2} / \mathrm{m}^{2}$ & $42.8 \pm 7.4$ & $52.2 \pm 8.9$ & 0.005 \\
\hline Albumin: $\mathrm{g} / \mathrm{dl}$ & $4.1 \pm 0.4$ & $4.1 \pm 0.5$ & 0.67 \\
\hline Hemoglobin: $\mathrm{g} / \mathrm{dl}$ & $12.6 \pm 2.3$ & $12.7 \pm 2.4$ & 0.78 \\
\hline PNI & $49.2 \pm 5.3$ & $49.2 \pm 7.0$ & 0.99 \\
\hline CEA: ng/ml & $7.4 \pm 21.2$ & $5.5 \pm 8.2$ & 0.50 \\
\hline \multicolumn{4}{|l|}{ Comorbidity } \\
\hline Diabetes mellitus & $11(16.2)$ & $8(15.7)$ & 0.94 \\
\hline Cardiac disease & $3(0.4)$ & $2(3.9)$ & 0.90 \\
\hline Type of gastrectomy & & & 0.01 \\
\hline Total gastrectomy & $19(27.9)$ & $26(51.0)$ & \\
\hline Distal gastrectomy & $49(72.1)$ & $25(49.0)$ & \\
\hline Type of approach & & & 0.26 \\
\hline Conventional & $3(4.4)$ & $5(9.8)$ & \\
\hline Laparoscopy & 65 (95.6) & $46(90.2)$ & \\
\hline Lymphadenectomy & & & 0.36 \\
\hline D1+ & $31(45.6)$ & $19(37.3)$ & \\
\hline D2 & $37(54.4)$ & $32(62.7)$ & \\
\hline Blood loss: ml & $383.6 \pm 660.8$ & $415.4 \pm 459.2$ & 0.76 \\
\hline Operation time: $\min$ & $312.5 \pm 91.4$ & $329.9 \pm 82.3$ & 0.28 \\
\hline \multicolumn{4}{|l|}{ Complication } \\
\hline$\geq$ grade 2 & $14(20.6)$ & $14(27.5)$ & 0.38 \\
\hline T stage & & & 0.43 \\
\hline $\mathrm{T} 1$ & 36 (52.9) & $19(37.3)$ & \\
\hline $\mathrm{T} 2$ & $9(13.2)$ & $12(23.5)$ & \\
\hline $\mathrm{T} 3$ & $15(22.1)$ & $14(27.5)$ & \\
\hline $\mathrm{T} 4$ & $8(11.8)$ & $6(11.8)$ & \\
\hline $\mathrm{N}$ stage & & & 0.93 \\
\hline No & $40(58.8)$ & $28(54.9)$ & \\
\hline N1 & $12(17.6)$ & $9(17.6)$ & \\
\hline N2 & $8(11.8)$ & $8(15.7)$ & \\
\hline N3 & $8(11.8)$ & $6(11.8)$ & \\
\hline TNM stage & & & 0.60 \\
\hline IA, IB & $37(54.4)$ & $23(45.1)$ & \\
\hline IIA, IIB & $18(26.5)$ & $16(31.4)$ & \\
\hline IIIA, IIIB, IIIC & $13(19.1)$ & $12(23.5)$ & \\
\hline Adjuvant chemotherapy & & & 0.30 \\
\hline Absent & $45(66.2)$ & $29(56.9)$ & \\
\hline Present & $23(33.8)$ & $22(43.1)$ & \\
\hline
\end{tabular}

BMI, body mass index; SMM index, skeletal muscle mass index; PNI, prognostic nutrition index; CEA, carcinoembryonic antigen. 
Table II. Univariate and multivariate analyses of clinicopathological factors associated with a loss of SMM $<5 \%$.

\begin{tabular}{|c|c|c|c|c|c|}
\hline \multirow[b]{2}{*}{ Factors } & \multirow[b]{2}{*}{$\mathrm{N}(\%)$} & \multicolumn{2}{|c|}{ Univariate analysis } & \multicolumn{2}{|c|}{ Multivariate analysis } \\
\hline & & OR $(95 \% \mathrm{CI})$ & P-value & OR $(95 \% \mathrm{CI})$ & P-value \\
\hline Age & $>7047(34.4)$ & $0.85(0.40-1.79)$ & 0.67 & & \\
\hline Gender & Male $80(67.2)$ & $1.81(0.82-4.02)$ & 0.15 & & \\
\hline \multirow[t]{2}{*}{ BMI } & $>2531(26.1)$ & $1.14(0.50-2.59)$ & 0.76 & & \\
\hline & $<189(7.6)$ & $2.89(0.69-12.2)$ & 0.15 & & \\
\hline SMM Index & Male: >50.7, Female: >44.6 58 (48.7) & $0.59(0.28-1.22)$ & 0.15 & & \\
\hline Type of gastrectomy & Total gastrectomy 45 (37.8) & $2.68(1.25-5.75)$ & 0.01 & $2.58(1.19-5.58)$ & 0.02 \\
\hline Approach & Conventional 8 (6.7) & $2.36(0.54-10.3)$ & 0.25 & & \\
\hline Lymphadenectomy & $\mathrm{D} 1+50(42.0)$ & $1.41(0.67-2.96)$ & 0.36 & & \\
\hline Blood loss & $>23060(50.4)$ & $1.19(0.58-2.47)$ & 0.63 & & \\
\hline Operation time & >30960 (50.4) & $1.37(0.66-2.84)$ & 0.40 & & \\
\hline Complication & $\geq$ Grade 228 (23.5) & $1.46(0.62-3.42)$ & 0.38 & & \\
\hline T stage & $\geq 264(53.8)$ & $1.90(0.90-3.98)$ & 0.09 & $1.78(0.83-3.82)$ & 0.14 \\
\hline $\mathrm{N}$ stage & $\geq 151(42.9)$ & $1.17(0.56-2.44)$ & 0.67 & & \\
\hline TNM stage & $\geq$ II $59(49.6)$ & $1.45(0.70-3.01)$ & 0.31 & & \\
\hline Adjuvant chemotherapy & Present 45 (37.8) & $1.48(0.70-3.14)$ & 0.30 & & \\
\hline
\end{tabular}

BMI, body mass index; SMM Index, skeletal muscle mass index; TNM, tumor-node-metastasis; OR, odds ratio; CI, confidence interval.

noted in patients who undergo total gastrectomy. Two reasons for this reduction in oral intake can be considered, namely loss of retention ability and/or decreases in ghrelin, an appetizing hormone that is released from the stomach. Ghrelin has various physiologic functions, including secretion of growth hormone, promotion of the appetite signal in the hypothalamus, and stimulation of gastrointestinal activity. It has been reported that the serum ghrelin level after total gastrectomy for gastric cancer decreases to $10 \%$ of its preoperative level (14).

The present study also revealed that SMM loss of $\geq 5 \%$ was an independent risk factor for OS, but not RFS. Similarly, in a previous study, preoperative sarcopenia was demonstrated to have associate with poor prognosis in gastric cancer after curative surgery (9). In other words, primary sarcopenia was a predictive factor of poor prognosis. On the other hand, although it is known that the patients' diet, body weight, SMM, and exercise capacity change after gastrectomy, no previous report has demonstrated the relationship between the change in SMM after gastrectomy and prognosis. To our knowledge, the present study is the first to analyze the postoperative SMM loss and determine its relationship with the survival of gastric cancer patients undergoing gastrectomy. As a predictor of OS, the rate of SMM loss after surgery was found to be more useful than the preoperative SMM.

There are numerous possible reasons for why the loss of SMM is a poor prognostic factor. Several studies have reported that sarcopenia is a poor prognostic factor of various malignant tumors (15). Further, Richards et al reported a strong association between sarcopenia and the presence of a systemic inflammatory response, including with the C-reactive protein and albumin levels, in patients with colorectal cancer (16), and Maggio et al showed that inflammatory cytokines may be involved in sarcopenia by interfering with insulin-like growth factor-1 signaling in skeletal muscle (17). A few studies have moreover reported that postoperative body weight loss is a poor prognostic factor after gastrectomy $(18,19)$. In these previous reports, the reasons for this finding were considered to be related to the immune response and decreases in dietary intake.

Aoyama et al reported that body weight loss or lean body mass loss was a risk factor associated with the continuation of adjuvant chemotherapy (20). In the present study, the relationship between loss of SMM and adjuvant chemotherapy was unclear. However, Aoyama et al reported that lean body mass and fat decreased after gastrectomy in the early postoperative period (12), and it is possible that the same change may occur in SMM. Accordingly, one of the reasons for the poor prognosis may be the fact that adjuvant chemotherapy cannot be continued in these patients.

The development of sarcopenia is associated with increased risks of falling, need for nursing care, and mortality. At the same time, the physical ability of patients with sarcopenia is reduced, and their living function is weakened, thus negatively affecting their quality of life. Clarifying the mechanisms of sarcopenia in patients with cancer may help reveal the mechanism of cachexia, the root of cancer death. Previous studies have shown that various methods of nutritional support are effective for improving dietary intake and outcomes in patients who lose weight after surgery $(21,22)$. Hatao et al found that the use of oral nutritional supplements after total gastrectomy significantly diminished postoperative weight loss (21). If oral nutritional supplements can be demonstrated to also be efficacious for preventing postoperative muscle mass reduction, such oral nutritional supplements could consequently be administered to patients with sarcopenia, which is an especially common finding after total gastrectomy. Further, 
Table III. Univariate and multivariate analyses of clinicopathological factors associated with relapse-free survival.

\begin{tabular}{|c|c|c|c|c|c|}
\hline \multirow[b]{2}{*}{ Factors } & \multirow[b]{2}{*}{$\mathrm{N}(\%)$} & \multicolumn{2}{|c|}{ Univariate analysis } & \multicolumn{2}{|c|}{ Multivariate analysis } \\
\hline & & HR $(95 \% \mathrm{CI})$ & P-value & HR $(95 \% \mathrm{CI})$ & P-value \\
\hline Age & $>7047(34.4)$ & $0.53(0.20-1.46)$ & 0.22 & & \\
\hline Gender & Male 80 (67.2) & $1.57(0.57-4.28)$ & 0.38 & & \\
\hline BMI & $>2531(26.1)$ & $0.95(0.37-2.48)$ & 0.92 & & \\
\hline & $<189(7.6)$ & $0.86(0.12-6.51)$ & 0.89 & & \\
\hline SMM Index & $\begin{array}{l}\text { Male: }>50.7, \text { Female: }>44.6 \\
58(48.7)\end{array}$ & $0.72(0.30-1.74)$ & 0.47 & & \\
\hline Type of gastrectomy & Total gastrectomy 45 (37.8) & $1.21(0.51-2.89)$ & 0.66 & & \\
\hline Approach & Conventional 8 (6.7) & $0.43(0.34-5.38)$ & 0.39 & & \\
\hline Lymphadenectomy & $\mathrm{D} 1+50(42.0)$ & $3.21(1.08-9.56)$ & 0.04 & $1.52(0.48-4.77)$ & 0.48 \\
\hline Blood loss & $>23060(50.4)$ & $2.12(0.82-5.48)$ & 0.12 & & \\
\hline Operation time & >309 $60(50.4)$ & $3.78(1.38-10.3)$ & 0.01 & $2.42(0.85-6.84)$ & 0.10 \\
\hline Complication & $\geq$ Grade $228(23.5)$ & $1.36(0.53-3.52)$ & 0.52 & & \\
\hline Histological grade & Undiff 62 (52.1) & $1.56(0.65-3.77)$ & 0.32 & & \\
\hline T stage & $\geq 264$ (53.8) & $5.78(1.70-19.6)$ & 0.005 & $1.46(0.24-8.88)$ & 0.68 \\
\hline $\mathrm{N}$ stage & $\geq 151(42.9)$ & $6.59(2.21-19.6)$ & 0.001 & $2.35(0.51-10.9)$ & 0.28 \\
\hline TNM stage & $\geq$ II 59 (49.6) & $7.18(2.11-24.4)$ & 0.002 & $0.80(0.06-11.8)$ & 0.87 \\
\hline Adjuvant chemotherapy & Present 45 (37.8) & $7.76(2.61-23.1)$ & 0.001 & $6.15(2.03-5.53)$ & 0.001 \\
\hline Loss of SMM & $\geq 5 \% 51(42.9)$ & $3.15(1.29-7.72)$ & 0.01 & $2.23(0.90-5.53)$ & 0.08 \\
\hline
\end{tabular}

BMI, body mass index; SMM Index, skeletal muscle mass index; Undiff, undifferentiated; TNM, tumor-node-metastasis; HR, hazard ratio; CI, confidence interval.

Table IV. Univariate and multivariate analyses of clinicopathological associated with overall survival.

\begin{tabular}{|c|c|c|c|c|c|}
\hline \multirow[b]{2}{*}{ Factors } & \multirow[b]{2}{*}{$\mathrm{N}(\%)$} & \multicolumn{2}{|c|}{ Univariate analysis } & \multicolumn{2}{|c|}{ Multivariate analysis } \\
\hline & & HR $(95 \% \mathrm{CI})$ & P-value & $\mathrm{HR}(95 \% \mathrm{CI})$ & P-value \\
\hline Age & $>7047(34.4)$ & $2.17(0.93-5.02)$ & 0.07 & $2.46(1.07-6.13)$ & 0.04 \\
\hline Gender & Male $80(67.2)$ & $0.84(0.35-2.00)$ & 0.70 & & \\
\hline BMI & $>2531(26.1)$ & $0.85(0.33-2.18)$ & 0.73 & & \\
\hline & $<189(7.6)$ & $2.00(0.46-8.66)$ & 0.36 & & \\
\hline SMM Index & $\begin{array}{l}\text { Male: }>50.7, \text { Female: }>44.6 \\
58(48.7)\end{array}$ & $0.86(0.37-2.01)$ & 0.73 & & \\
\hline Type of gastrectomy & Total gastrectomy 45 (37.8) & $0.85(0.36-2.03)$ & 0.72 & & \\
\hline Approach & Conventional 8 (6.7) & $0.61(0.08-4.57)$ & 0.63 & & \\
\hline Lymphadenectomy & $\mathrm{D} 1+50(42.0)$ & $1.68(0.68-4.12)$ & 0.26 & & \\
\hline Blood loss & $>23060(50.4)$ & $1.27(0.53-3.05)$ & 0.60 & & \\
\hline Operation time & >309 $60(50.4)$ & $1.82(0.76-4.34)$ & 0.18 & & \\
\hline Complication & $\geq$ Grade 228 (23.5) & $1.60(0.65-3.92)$ & 0.31 & & \\
\hline Histological grade & Undiff $62(52.1)$ & $1.34(0.57-3.14)$ & 0.50 & & \\
\hline T stage & $\geq 264(53.8)$ & $3.08(1.14-9.37)$ & 0.03 & $1.47(0.28-7.77)$ & 0.65 \\
\hline $\mathrm{N}$ stage & $\geq 151(42.9)$ & $2.07(0.88-4.87)$ & 0.09 & $1.12(0.37-3.43)$ & 0.84 \\
\hline TNM stage & $\geq 259(49.6)$ & $2.94(1.15-7.53)$ & 0.03 & $2.65(1.03-6.84)$ & 0.04 \\
\hline Adjuvant chemotherapy & Present 45 (37.8) & $1.90(0.82-4.42)$ & 0.14 & & \\
\hline Loss of SMM & $\geq 5 \% 51(42.9)$ & $2.40(1.02-5.62)$ & 0.04 & $2.57(1.07-6.13)$ & 0.03 \\
\hline
\end{tabular}

BMI, body mass index; SMM Index, skeletal muscle mass index; Undiff, undifferentiated TNM, tumor-node-metastasis; HR, hazard ratio; CI, confidence interval. 
A

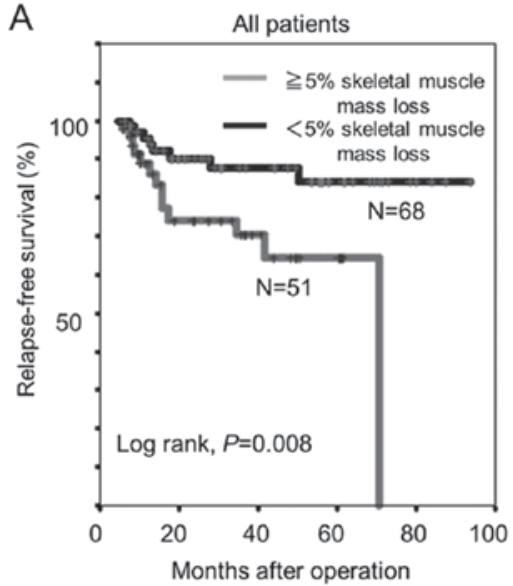

B

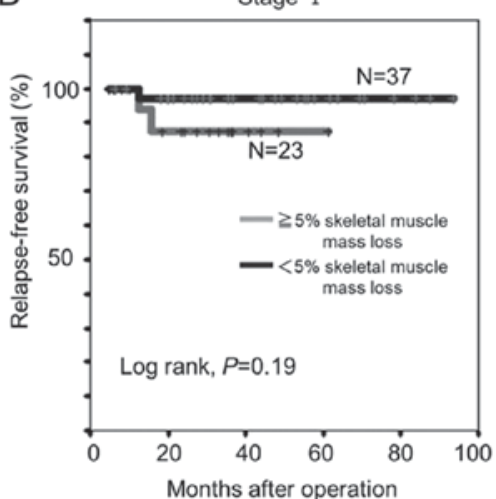

C

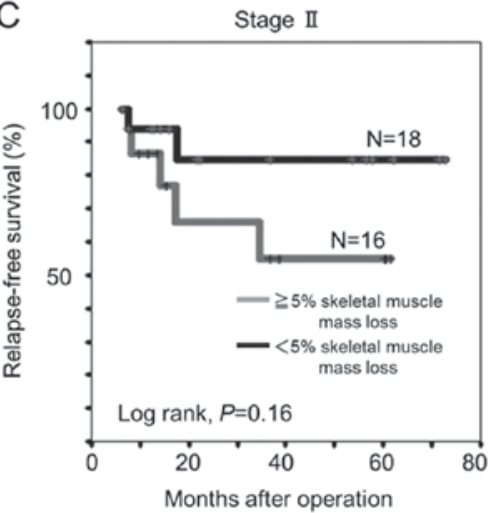

D

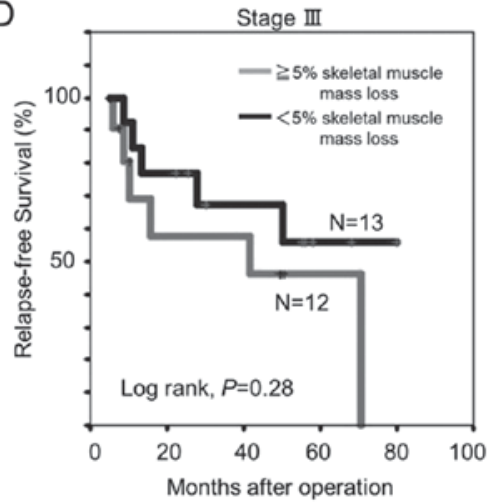

$\mathrm{E}$

All patients

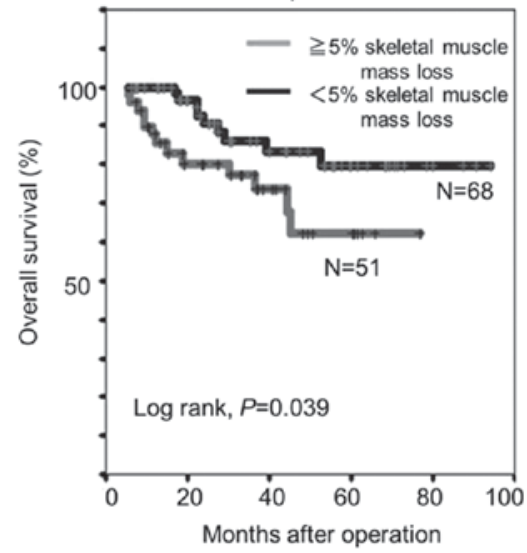

$\mathrm{F}$

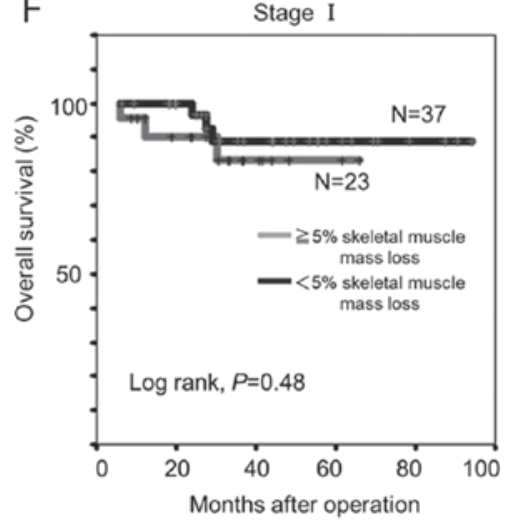

G

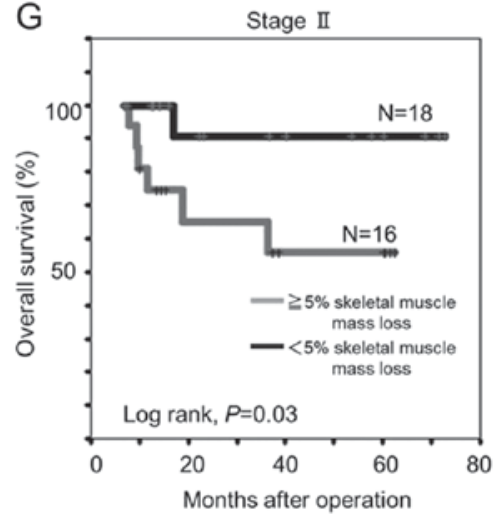

$\mathrm{H}$

Stage III

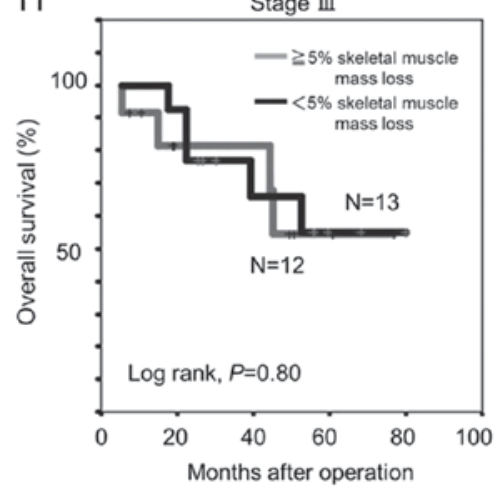

Figure 2. Relapse-free and overall survival Kaplan-Meier survival curves in patients with a SMM $<5$ vs. $\geq 5 \%$ after gastrectomy. (A) All patients, (B) stage I, (C) stage II, and (D) stage III patients. Overall survival curve in patients with a SMM $<5$ vs. $\geq 5 \%$ after gastrectomy. (E) All patients, (F) stage I, (G) stage II, and $(\mathrm{H})$ stage III patients. SMM, skeletal muscle mass.

a phase II trial was recently performed to examine the effect of ghrelin in patients who had undergone total gastrectomy, as a means of preventing body weight loss (23). In another study, the administration of synthetic ghrelin successfully 
lessened the postoperative body weight loss and improved appetite and food intake after total gastrectomy (24). Thus, the administration of oral nutritional supplements or ghrelin after gastrectomy may help to prevent postoperative sarcopenia. Consistent with this suggestion, a prior study found that increased ghrelin signaling improved skeletal muscle atrophy in an aged mouse model (25).

The current study has some limitations. First, this was a retrospective single-center study with a limited number of patients. The body weight index is one of the most common parameters used to represent nutritional status. However, herein, we did not evaluate the changes in body weight of the patients. Moreover, we did not measure the SMM in the early postoperative period. Thereby, we could not clarify exactly when the SMM decreased postoperatively. If the SMM decreases early in the postoperative period, the cause of muscle mass loss may be the invasiveness of the surgery itself or postoperative complications. If the SMM decreases after discharge, it may be due to a decrease in dietary quantity or the use of adjuvant chemotherapy. Further research is necessary to clarify these issues.

In conclusion, the present study revealed that total gastrectomy was a significant and independent risk factor for SMM losses of $\leq 5 \%$ at 6 months after gastrectomy. Moreover, we found that the postoperative SMM is a novel predictive marker of poor prognosis.

\section{Competing interests}

The authors declare that they have no competing interests.

\section{References}

1. Rosenberg I: Summary comments: Epidemiological and methodological problems in determining nutritional status of older persons. Am J Clin Nutr 50: 1231-1233, 1989.

2. Harimoto N, Yoshizumi T, Shimokawa M, Sakata K, Kimura K, Itoh S, Ikegami T, Ikeda T, Shirabe K and Maehara Y: Sarcopenia is a poor prognostic factor following hepatic resection in patients aged 70 years and older with hepatocellular carcinoma. Hepatol Res 46: 1247-1255, 2016

3. Suzuki Y, Okamoto T, Fujishita T, Katsura M, Akamine T, Takamori S, Morodomi Y, Tagawa T, Shoji F and Maehara Y: Clinical implications of sarcopenia in patients undergoing complete resection for early non-small cell lung cancer. Lung Cancer 101: 92-97, 2016.

4. Hirasawa Y, Nakashima J, Yunaiyama D, Sugihara T, Gondo T, Nakagami Y, Horiguchi Y, Ohno Y, Namiki K, Ohori M, et al: Sarcopenia as a novel preoperative prognostic predictor for survival in patients with bladder cancer undergoing radical cystectomy. Ann Surg Oncol 23 (Suppl 5): S1048-S1054, 2016.

5. Tan BH, Birdsell LA, Martin L, Baracos VE and Fearon KC: Sarcopenia in an overweight or obese patient is an adverse prognostic factor in pancreatic cancer. Clin Cancer Res 15 6973-6979, 2009.

6. Sabel MS, Lee J, Cai S, Englesbe MJ, Holcombe S and Wang S: Sarcopenia as a prognostic factor among patients with stage III melanoma. Ann Surg Oncol 18: 3579-3585, 2011

7. Miyamoto Y, Baba Y, Sakamoto Y, Ohuchi M, Tokunaga R, Kurashige J, Hiyoshi Y, Iwagami S, Yoshida N, Yoshida M, et al: Sarcopenia is a negative prognostic factor after curative resection of colorectal cancer. Ann Surg Oncol 22: 2663-2668, 2015.

8. Miyamoto Y, Baba Y, Sakamoto Y, Ohuchi M, Tokunaga R, Kurashige J, Hiyoshi Y, Iwagami S, Yoshida N, Watanabe M and Baba H: Negative impact of skeletal muscle loss after systemic chemotherapy in patients with unresectable colorectal cancer. PLoS One 10: e0129742, 2015.
9. Zhuang CL, Huang DD, Pang WY, Zhou CJ, Wang SL, Lou N, Ma LL, Yu Z and Shen X: Sarcopenia is an independent predictor of severe postoperative complications and long-term survival after radical gastrectomy for gastric cancer: Analysis from a large-scale cohort. Medicine (Baltimore) 95: e3164, 2016.

10. Aoyama T, Sato T, Segami K, Maezawa Y, Kano K, Kawabe T, Fujikawa H, Hayashi T, Yamada T, Tsuchida K, et al: Risk factors for the loss of lean body mass after gastrectomy for gastric cancer. Ann Surg Oncol 23: 1963-1970, 2016.

11. Yamaoka Y, Fujitani K, Tsujinaka T, Yamamoto K, Hirao M and Sekimoto M: Skeletal muscle loss after total gastrectomy, exacerbated by adjuvant chemotherapy. Gastric Cancer 18: 382-389, 2015.

12. Aoyama T, Kawabe T, Fujikawa H, Hayashi T, Yamada T, Tsuchida K, Yukawa N, Oshima T, Rino Y, Masuda M, et al: Loss of lean body mass as an independent risk factor for continuation of S-1 adjuvant chemotherapy for gastric cancer. Ann Surg Oncol 22: 2560-2566, 2015

13. Aoyama T, Kawabe T, Hirohito F, Hayashi T, Yamada T, Tsuchida K, Sato T, Oshima T, Rino Y, Masuda M, et al: Body composition analysis within 1 month after gastrectomy for gastric cancer. Gastric Cancer 19: 645-650, 2016.

14. Takachi K, Doki Y, Ishikawa O, Miyashiro I, Sasaki Y, Ohigashi H, Murata K, Nakajima H, Hosoda H, Kangawa K, et al: Postoperative ghrelin levels and delayed recovery from body weight loss after distal or total gastrectomy. J Surg Res 130: 1-7, 2016.

15. Joglekar S, Nau PN and Mezhir JJ: The impact of sarcopenia on survival and complications in surgical oncology: A review of the current literature. J Surg Oncol 112: 503-509, 2015.

16. Richards $\mathrm{CH}$, Roxburgh CS, MacMillan MT, Isswiasi S, Robertson EG, Guthrie GK, Horgan PG and McMillan DC: The relationships between body composition and the systemic inflammatory response in patients with primary operable colorectal cancer. PLoS One 7: e41883, 2012.

17. Maggio M, De Vita F, Lauretani F, Buttò V, Bondi G, Cattabiani C, Nouvenne A, Meschi T, Dall'Aglio E and Ceda GP: IGF-1, the cross road of the nutritional, inflammatory and hormonal pathways to frailty. Nutrients 5: 4184-4205, 2013.

18. Lee HH, Park JM, Song KY, Choi MG and Park CH: Survival impact of postoperative body mass index in gastric cancer patients undergoing gastrectomy. Eur J Cancer 52: 129-137, 2016.

19. Kubo H, Komatsu S, Ichikawa D, Kawaguchi T, Kosuga T, Okamoto K, Konishi H, Shiozaki A, Fujiwara H and Otsuji E: Impact of body weight loss on recurrence after curative gastrectomy for gastric cancer. Anticancer Res 36: 807-813, 2016.

20. Aoyama T, Yoshikawa T, Shirai J, Hayashi T, Yamada T, Tsuchida K, Hasegawa S, Cho H, Yukawa N, Oshima T, et al: Body weight loss after surgery is an independent risk factor for continuation of S-1 adjuvant chemotherapy for gastric cancer. Ann Surg Oncol 20: 2000-2006, 2013.

21. Hatao F, Chen KY, Wu JM, Wang MY, Aikou S, Onoyama H, Shimizu N, Fukatsu K, Seto Y and Lin MT: Randomized controlled clinical trial assessing the effects of oral nutritional supplements in postoperative gastric cancer patients. Langenbecks Arch Surg 402: 203-211, 2017.

22. Imamura $H$, Nishikawa K, Kishi K, Inoue K, Matsuyama J, Akamaru Y, Kimura Y, Tamura S, Kawabata R, Kawada J, et al: Effects of an oral elemental nutritional supplement on postgastrectomy body weight loss in gastric cancer patients: A randomized controlled clinical trial. Ann Surg Oncol 23: 2928-2935, 2016.

23. Adachi S, Takiguchi S, Okada K, Yamamoto K, Yamasaki M, Miyata H, Nakajima K, Fujiwara Y, Hosoda H, Kangawa K, et al: Effects of ghrelin administration after total gastrectomy: A prospective, randomized, placebo-controlled phase II study. Gastroenterology 138: 1312-1320, 2010.

24. Takiguchi S, Hiura Y, Takahashi T, Kurokawa Y, Yamasaki M, Nakajima K, Miyata H, Mori M, Hosoda H, Kangawa K and Doki Y: Effect of rikkunshito, a Japanese herbal medicine, on gastrointestinal symptoms and ghrelin levels in gastric cancer patients after gastrectomy. Gastric Cancer 16: 167-174, 2013.

25. Fujitsuka N, Asakawa A, Morinaga A, Amitani MS, Amitani H, Katsuura G, Sawada Y, Sudo Y, Uezono Y, Mochiki E, et al: Increased ghrelin signaling prolongs survival in mouse models of human aging through activation of sirtuin1. Mol Psychiatry 21: 1613-1623, 2016. 